International Journal of Agricultural Research 6 (5): 420-428, 2011

ISSN 1816-4897 / DOI: 10.3923/ijar.2011.420.428

(C) 2011 Academic Journals Inc.

\title{
Prototype of Harvesting System for Some Aromatic and Medical Plants
}

\author{
${ }^{1}$ R.A. Hegazy, ${ }^{1}$ G. Molari and ${ }^{2}$ A.M. El-Sheikha \\ ${ }^{1}$ Department of Agricultural Economic and Engineering, Bologna University, Italy \\ ${ }^{2}$ Department of Agricultural Engineering, Faculty of Agriculture, Kafrelsheikh University, Egypt \\ Corresponding Author: R.A. Hegazy, Department of Agricultural Engineering, Faculty of Agriculture, \\ Kafrelsheikh University, Egypt
}

\begin{abstract}
Although aromatic and medical plants have vital benefits and importance for producers or users, still there is lack of research on harvesting machines which can be used to harvest and collect these types of plants. So, the purpose of this study was to design a new harvesting prototype for cutting and collecting different types of these plants. The main components of the experimental harvester are: engine with traveling mechanism, cutting unit and conveying unit connected with storage tank. The design concepts were related to cultivation, environmental factors for these types of plants. The general performance of the prototype for harvesting three types of aromatic and medical plants showed that the working time taken by the machine to collect sage was higher than time taken to collect rosemary and winter savoy by 16 and $12 \%$, respectively, where average values of fuel consumption for sage, rosemary and winter savory were $0.32,0,27$ and $0.30 \mathrm{~kg} \mathrm{kWh}^{-1}$, respectively. Machine working efficiency varied from 28.5 to $36.9 \mathrm{~m}^{2} \mathrm{~min}^{-1}$ for all plants. Best working efficiency values obtained by using machine with rosemary. There were increasing in harvesting losses for sage and rosemary by 15.4 and $14 \%$ compared to winter savory, also number of transferred plants incase of winter savory was high and gave best transfer efficiency by $89.2 \%$ on average. Generally, the performance of the prototype demonstrated clear results about harvesting specific plants successfully. More effective use for such machine will be continue with further modifications for this prototype.
\end{abstract}

Key words: Small herbs harvester, automatic harvesting, travelling mechanism, cutting disks, conveying system

\section{INTRODUCTION}

The production of aromatic and medical plants (Rosemary, Thyme, Coriander, Sage, Marjoram ...etc.) has been extensively focused in the last 30 years and these plants have moved from minor agricultural plants to into crops that many farmers consider producing as an alternative to usual plantings of food and feed crops (Ammarellou et al., 2007). Most developing countries are endowed with vast resources of aromatic and medical plants. These plants have been used over the millennia for human welfare in between man and his environment, even today as a large proportion of people in developing countries still live in rural areas and are precluded from the luxury of access to modern therapy, mainly for economic reasons. At present, $80 \%$ of the population in developing countries relies largely on plant-based drugs for their health care needs and 
according to the World Health Organization (WHO) has the in coming decades a similar percentage may well rely on plant-based medicines. From 25 to 30\% of the drugs sold worldwide contain compounds derived from plant material (WHO, 2003; Gurib-Fakim, 2006). The Chinese leadership this sector with largest planted area and is some $20 \%$ greater than the USA, the second largest supplier, beside, Republic of Korea, Chile, India, Brazil and Thailand. In Europe where the phytomedicine industry is thriving, extracts from medicinal plants are sold in a purified form for the treatment and prevention of all kinds of diseases as natural products. Now-a-days traditional medicine is considered more for its capacity to generate other medicine than for its own sake (Abdel-Azim et al., 2011). In Italy, different studies have been carried out especially in Central-Southern Italy (Pieroni et al., 2002). Natale and Pollio (2007) and Guarrera et al. (2008) reported popular uses in Italy for hundreds of these plants. But still Germany is the main importers of medicinal plants and also a major international producer and exporter of medicines.

Using labors and hand tools in harvesting and packing aromatic and medical plants became not practical in its production especially after it had planted in wide area in all over the world. In addition to that, these methods for harvesting aromatic and medical plants are receiving scrutiny as concerns regarding a dwindling labor supply and increase global competition continue to evolve (Diekmann, 2002). However, the efficiency of several mechanically harvested crops will need to improve in order to remain profitable and competitive with production from other countries. Currently, most existing mechanical harvesting systems tend to produce lower yields, with higher field losses when compared to hand-harvest production systems (Hassani et al., 2011). This is a function of both the performance of the harvesters as well as the architectural and plant characteristics (Akay et al., 2004).

There are specific numbers of studies that can describe new systems to harvest aromatic and medical plants. In addition, beside, there are another studies have set new techniques to harvest small plants and vegetables which are the closest in characteristics of aromatic and medical plants. Studying cultivation conditions and machine-plant harvesting system will likely to be best strategy for developing an effective harvester. According to the previous strategy, Chang et al. (2004) developed an automated harvesting system for Edible Perilla leaves. The harvester consisted of picking system, traveling mechanism, conveying equipment and controlling equipment. The leaf picking system was tested in field and gave around $50 \%$ of harvesting loss with damaged rate of harvested leaves and stems of plant by $11.67 \%$. For conveying equipment, belt conveyor of cleat type was used. In addition, a lot of plants such vegetables, herbs and aromatic can be moved by many types of Belts, chains, rollers, pneumatics, gravity flow devices, augers and combinations thereof are in common use. These components are employed to physically transport plants from one location to another during cutting, processing and/or harvesting operations; many of those methods have been described (Funk and Walker, 2009).

Another important concept is once-over mechanical harvesting system which study characterizes plant architecture and harvester recovery data where a mechanical harvesting index was used for future screening of bean cultivars and header designs (James et al., 2004). Using same aspects in above mentioned studies used by Sidahmed and Jaber (2004) to design and test a cutter mechanism for mechanical harvesting of lentils which cuts and collects shoots. Its performance was high compared to hand harvesting and shattering losses of seed and straw were not significantly different from that which occurred in hand harvesting. The designed machine also allowed harvesting at a sufficiently low cutting height to recover pods growing close to the ground while not being affected by the presence of stones. This design can overcome problem impeding 
mechanical harvesting of some medical and aromatic plants, specialty these plants are growing close to the ground which requires a low cutting height as recommended earlier (Khayrallah, 1981; Erskine et al., 1990).

Until the operation for harvesting is just cutting and transporting of the plant, using self propelled harvesters wasn't the only available solution for development high effective way to facilitate harvesting such type of plants. Another methods have been tested such using two wheel tractor to provide required power to some harvesting tools (Rojanasaroj et al., 2003). Many farm equipments can utilize harvesting many types of aromatic and medical plants, for example in Italy, a mower harvester to be used to cut lavender. Forage equipment, self-propelled mower with loader and mower with oscillating blades often the machine of choice to harvest mint (Piccarolo, 2009). Adding new technology to harvesting machine parts is also another important concept to increase the accuracy of operation, Huang et al. (2010) conducted a research study to design a kind of gripping-belt speed automatic tracking system of traditional Chinese herbal harvester by AT89C52 single-chip micro computer as a core combined with fuzzy PID control algorithm. The main advantage that the system can adjust the gripping-belt speed in accordance with the variation of the machine's operation, so there is a perfect matching between the machine operation speed and the gripping-belt speed. And the harvesting performance of the machine can be improved greatly by using System design which includes hardware and software (Koloor and Kiani, 2007).

Taking above mentioned aspects in consideration, the continued development of highly efficient, highly mechanized systems is essential. This will make the production of aromatic and medical plants are to remain viable in the world. Also, it's clear that there is lack of research on development such type of mechanical harvesting machine which can be used specifically in harvesting and collecting aromatic and medical plants. So the main goal for present study was to develop a small prototype of harvesting and storage system for some aromatic and medical plant and to test its performance, after taking plant characteristics in consideration.

\section{MATERIALS AND METHODS}

A new harvesting prototype for cutting and collecting different type of aromatic and medical plants was developed. The main components of the experimental harvester are: engine with traveling mechanism, cutting unit and conveying unit connected with storage tank.

Engine and traveling mechanism: The engine used in this study was 4 -strok petrol providing $2.95 \mathrm{~kW}$ with one forward speed, the engine provide motion to two wheels as a traveling mechanism with $3.5 / 6 \mathrm{~km} \mathrm{~h}^{-1}$. The engine is attached with rotating arm as transmission link working as p.t.o with 943 r.p.m anti-clockwise. The used engine was a part of multi-use machine was manufactured by Grillo Spa in Italy (Fig. 1).

Cutting unit: The developed cutting unit consisted of two discs, one was notched disc with outside sharp edge and $230 \mathrm{~mm}$ diameter, this disc was made of steel $2 \mathrm{~mm}$ thickness. The disc has 50 sharp teeth around its perimeter and rotating with 943 r.p.m. The second disc was grooved one with $200 \mathrm{~mm}$ diameter, $4 \mathrm{~mm}$ groove and this disc was made of cast iron and fixed in the carrying frame of the machine. Using this type of cutting system is ideal to provide adequate cut to plants which fall between the two discs. Both discs were fitted to carrying frame which the cutting disc was connected to inner circle of ball bearing from its down side, both bearing and cutting disc are fit on its specific place. The upper side of cutting disc is connected with meshing part of rotating arm in the engine transmission link while the grooved disc is fixed to the carrying frame with free movement (Fig. 2). 

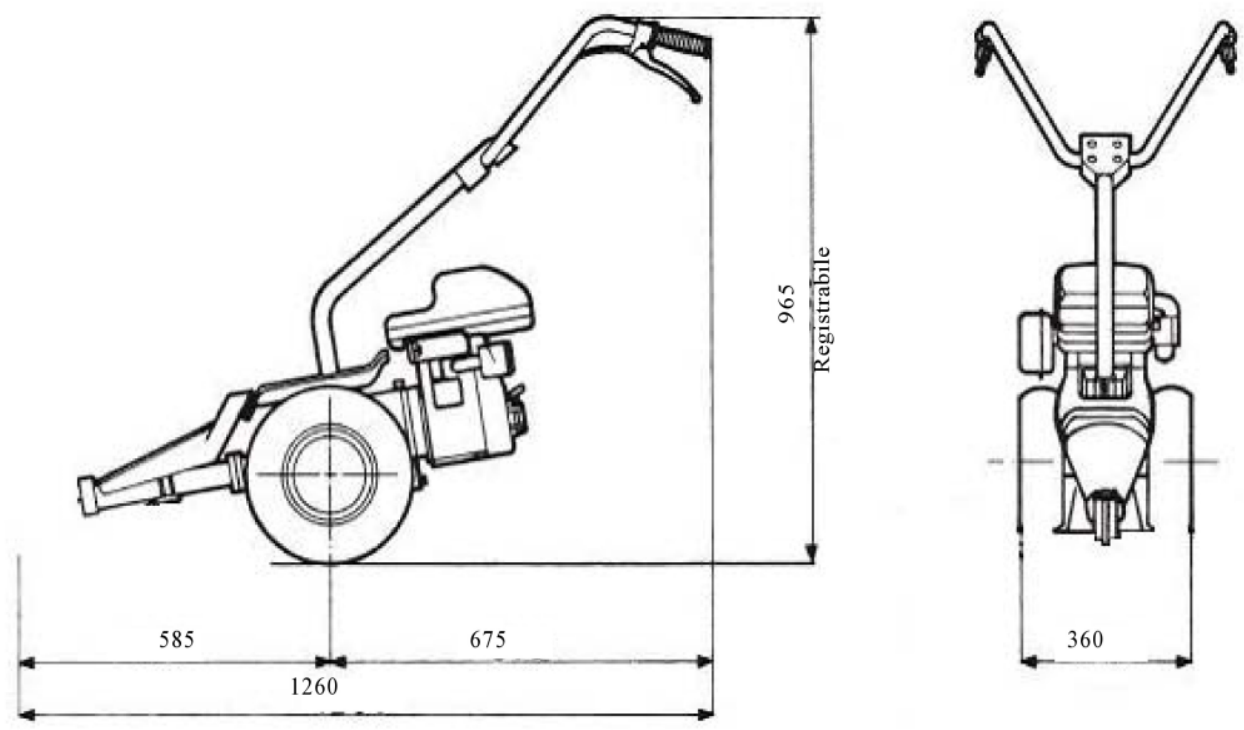

Fig. 1: Engine and its traveling mechanism used in the experiments
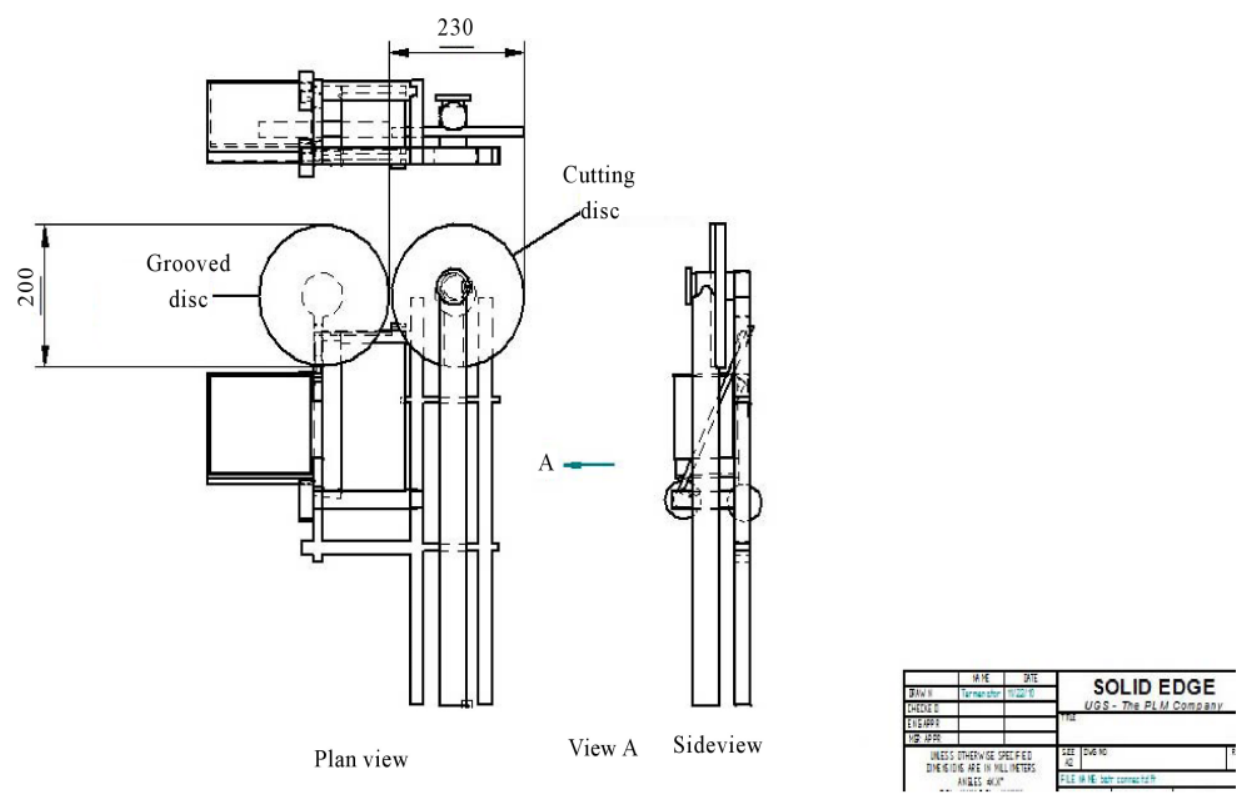

Fig. 2: Cutting system fixed on the main frame

Conveying unit and storage tank: The conveying unit was consisted of two main parts. First part is a plant transferring system which used to collect the plants and push them towards the cutting unit as well as moving them towards the belt and storage tank. This part consisted of a vertical shaft with angular orientation fixed teeth in reference of a vertical axle of the shaft, rotating between a couple of plants harvesting guide; this shaft was provided by motion by different belt and bullies which take the motion mainly from meshing part of rotating arm in the engine transmission link by using a v-belt as shown in Fig. 3.

The second part is an endless belt which fall directly behind the cutting unit. The engine wheels provide the necessary motion to the belt conveyor. All moving parts are covered for safety. 
Field experiments: The field experiments were carried out in Casalecchio Di Reno region, Bologna, Italy from 15th to 22nd October 2010. The existed herbs and aromatic plants in experimental area were Salvia, Rosemary and winter savory. Soil water content measured with oven-dry at time of experiments was $0.44 \mathrm{~m}^{3} \mathrm{~m}^{-3}$ at bulk density $0.52 \mathrm{~g} \mathrm{~cm}^{-3}$ the planted herbs rows kept at $25 \mathrm{~m}$ length at the time of experiments with three replications each. The plant features and characteristics are giving in Table 1.

Variables and measurements: For testing the harvesting prototype in the field, many independent parameters are determined to show the operating performance of the machine under different conditions.

Estimation and analysis of losses: For calculating rate of harvesting loss, the following Equation can be used:

$$
\mathrm{Lh}=\frac{\mathrm{Gh}}{\mathrm{Gc}+\mathrm{Gh}} \times 100
$$

Table 1: Features and characteristics of harvested herbal and aromatic plants

Harvested plants (m)

\begin{tabular}{lccc} 
Features & Sage (Salvia officinalis) & Rosemary (Rosmarinus officinalis) & Winter savory (Satureja montana) \\
\hline Average plant height & 0.420 & 0.280 & 0.300 \\
Average plant width & 0.170 & 0.250 & 0.140 \\
Average stem diameter & 0.008 & 0.011 & 0.006 \\
Average plant spacing & 0.420 & 0.310 & 0.230 \\
\hline
\end{tabular}

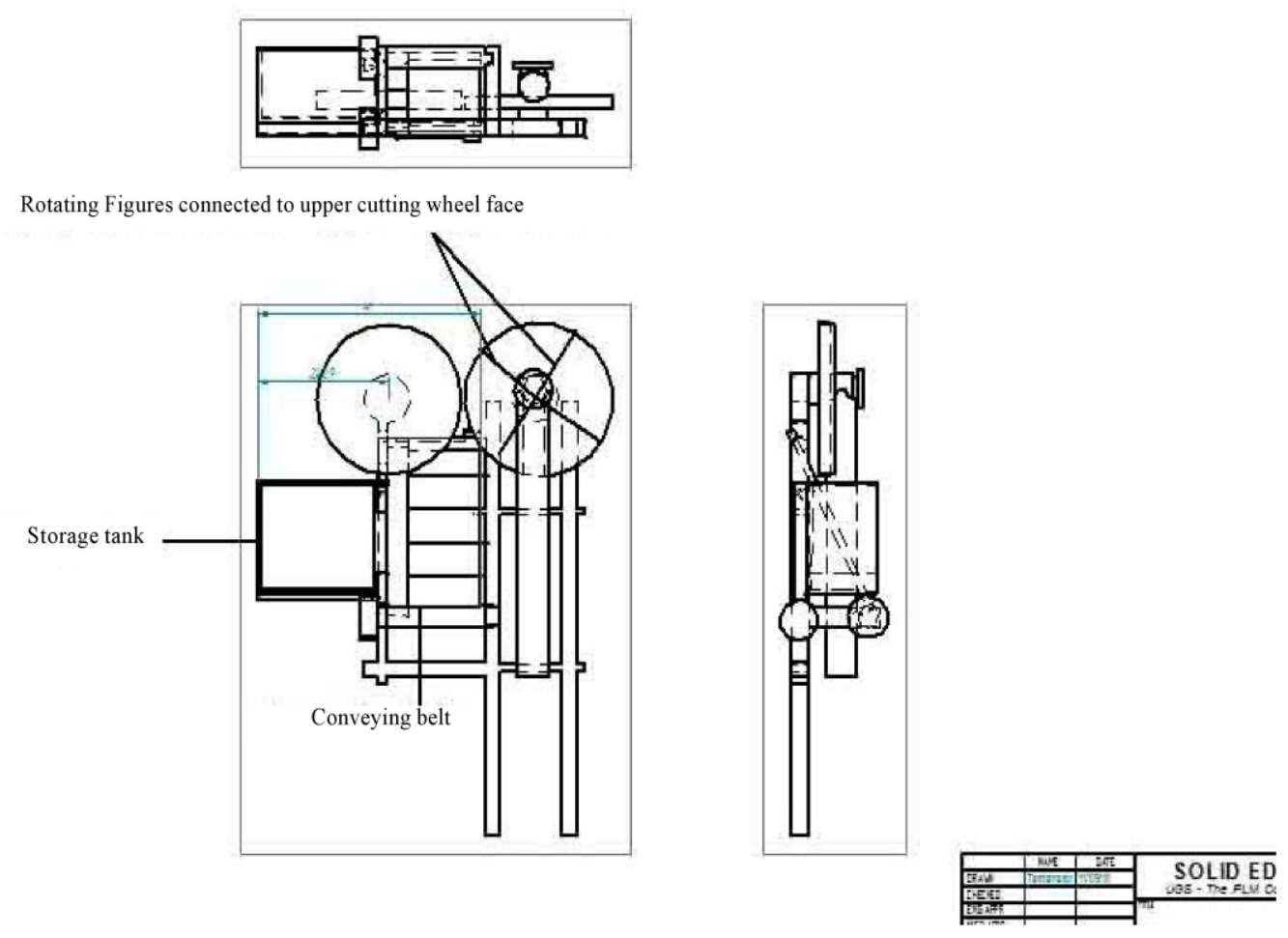

Fig. 3: Plant transferring system 
Where:

Lh = Rate of harvesting loss (\%)

$\mathrm{Gc}=$ Harvested no. of plants in measured area

$\mathrm{Gh}=$ No. of lost plants

For calculating the transfer rate, the following equation can be used:

$$
\mathrm{T}=\frac{\mathrm{Td}}{\mathrm{Gc}} \times 100
$$

Where:

$\mathrm{T}=$ Transfer rate $(\%)$

$\mathrm{Td}=$ No. of transferred plants

$\mathrm{Gc}=$ No. of harvested plants in measured area

Fuel consumption and time required: The time used in harvesting was recorded to calculate the field capacity and efficiency. The corresponding fuel consumption was measured by filling the used volume into the fuel tank which was full at the beginning of the test. and then working efficiency can estimated from following Equation:

$$
\mathrm{D}=\frac{\mathrm{A}}{\mathrm{T}}
$$

Where:

$\mathrm{D}=$ Working efficiency $\left(\mathrm{m} \mathrm{min}^{-1}\right)$

$\mathrm{A}=$ Working area $\left(\mathrm{m}^{2}\right)$

$\mathrm{T}=$ Working time $(\mathrm{min})$

In addition, several stand and harvesting metrics were measured like damage plants and number of plats transferred into the tank to evaluate the performance of conveyer belt system.

Statistical analysis: Analysis of Variance was used to determine significances of difference harvesting parameters related the prototype performance. XLSTAT package was used at 0.05 level of significance.

\section{RESULTS AND DISCUSSION}

General performance test of the prototype: The general harvest performance of the prototype was tested in the field and preened in Table 2 . The measurements used to collect a general idea about the performance were working time, fuel consumption and machine working efficiency. Average machine working time for sage, rosemary and winter savoy was $0.75,0.63$ and $0.66 \mathrm{~min}$, respectively with standard deviation 0.061 . The working time taken by the machine to collect sage was higher than time taken to collect rosemary and winter savoy by 16 and $12 \%$, respectively and this maybe due to delay in collecting the plant which was higher than the other two plants and more time to handle most of the plant height. Average amount of consumed fuel by the machine had the same trend related to the time taken but with standard deviation 0.022 , where average values of fuel consumption for sage, rosemary and winter savory were $0.32,0.27$ and $0.30 \mathrm{~kg} \mathrm{kWh}{ }^{-1}$, respectively. This amount of fuel consumption is lower than amount 
Int. J. Agric. Res., 6 (5): 420-428, 2011

Table 2: Working time, fuel consumption and working efficiency of the prototype for three different plants

\begin{tabular}{lccccc}
\hline $\begin{array}{l}\text { Plants } \\
\text { plants }\end{array}$ & Replications & $\begin{array}{c}\text { Machine working } \\
\text { time }(\mathrm{min})\end{array}$ & $\begin{array}{c}\text { Fuel consumption } \\
\left(\mathrm{kg} \mathrm{kWh}^{-1}\right)\end{array}$ & $\begin{array}{l}\text { Working efficiency } \\
\left(\mathrm{m}^{2} \mathrm{~min}^{-1}\right)\end{array}$ \\
\hline Sage & 59 & $\mathrm{R} 1$ & 0.72 & 0.32 & 31.25 \\
& 61 & $\mathrm{R} 2$ & 0.75 & 0.31 & 30.00 \\
Average & 61 & $\mathrm{R} 3$ & 0.79 & 0.33 & 28.50 \\
Rosemary & 60 & & 0.75 & 0.32 & 29.90 \\
& 80 & $\mathrm{R} 1$ & 0.64 & 0.27 & 35.20 \\
Average & 82 & $\mathrm{R} 2$ & 0.63 & 0.28 & 35.70 \\
Winter sav ory & 81 & $\mathrm{R} 3$ & 0.61 & 0.27 & 36.90 \\
& 113 & & 0.63 & 0.29 & 35.90 \\
Average & 105 & $\mathrm{R} 1$ & 0.67 & 0.29 & 34.60 \\
Standard deviation & 110 & $\mathrm{R} 2$ & 0.66 & 0.31 & 35.16 \\
\hline
\end{tabular}

Table 3: Harvesting losses and transfere efficiency of prototype under diffrent three plants

\begin{tabular}{lcccccc}
\hline Plants & $\begin{array}{l}\text { No. of } \\
\text { harvested plants }\end{array}$ & $\begin{array}{l}\text { No. of } \\
\text { lost plants }\end{array}$ & $\begin{array}{l}\text { Harvesting } \\
\text { losses (\%) }\end{array}$ & $\begin{array}{l}\text { No. of damaged } \\
\text { plants }\end{array}$ & $\begin{array}{l}\text { No. of transferred } \\
\text { plants into tank }\end{array}$ & $\begin{array}{l}\text { Transfer } \\
\text { efficiency }\end{array}$ \\
\hline Sage & 48 & 11 & 18.60 & 7 & 41 & 85.40 \\
& 50 & 11 & 18.00 & 10 & 40 & 80.00 \\
Average & 49 & 12 & 19.70 & 8 & 41 & 83.70 \\
Rosemary & 49 & 11 & 18.80 & 8 & 41 & 83.00 \\
& 66 & 14 & 17.50 & 23 & 43 & 65.20 \\
& 67 & 15 & 18.30 & 23 & 44 & 65.70 \\
Average & 65 & 16 & 19.80 & 22 & 43 & 66.20 \\
Winter savory & 66 & 15 & 18.50 & 23 & 43 & 65.70 \\
& 96 & 17 & 15.00 & 12 & 84 & 87.50 \\
& 88 & 17 & 16.20 & 6 & 82 & 93.20 \\
Average & 92 & 18 & 16.40 & 12 & 80 & 86.90 \\
Standard deviation & 92 & 17 & 15.90 & 10 & 82 & 89.20 \\
\hline
\end{tabular}

consumed by the small soybean harvester used by Rojanasaroj et al. (2003), due to different engines and the time required to collect soybean.

Machine working efficiency varied from 28.5 to $36.9 \mathrm{~m}^{2} \mathrm{~min}^{-1}$ for all plants with standard deviation 2.842. Best working efficiency values obtained by using machine with rosemary with average of $35.9 \mathrm{~m}^{2} \mathrm{~min}^{-1}$ followed by using the machine with winter savory and sage, respectively. Increasing in the working efficiency with rosemary is due to less working time of the machine at fixed working area compared to the other plants.

Harvesting performance: Table 3 details the results obtained by using the prototype during harvesting process. Harvesting losses were calculated for each plant and the average values for sage, rosemary and winter savory were $18.8,18.5$ and $15.9 \%$, respectively with standard deviation 1.618. Increasing in harvesting losses for sage and rosemary by 15.4 and $14 \%$ compared to winter savory due to the higher stem diameter and plant height which make cutting process for the prototype is more difficult. In case of winter savory the higher number of harvested plants does not affect the cutting process but the plant root and height can make some obstacles during the 
harvesting operation. General rate of harvesting losses was relatively high but this agree with the results obtained by Chang et al. (2004) during performance test of automated harvesting system for edible perilla leaves on the other hand, the harvesting losses were much higher than results obtained by Sidahmed and Jaber (2004).

Conveying performance: Transfer efficiency for the harvested plants into the storage tank varied from plat to plant and even within replications. Number of transferred plants incase of winter savory was high and gave best transfer efficiency by $89.2 \%$ on average. The transfer efficiency for sage varied from 80 to $85.4 \%$ and its average was higher than average of transfer efficiency for rosemary $20.8 \%$. The standard deviation in this case was 10.786 (Table 3). The low values of transfer efficiency for rosemary maybe due to the large plant width for the plat compared to other plants which agree with James et al. (2004) during his investigation about mechanical harvesting index for rating the architectural characteristics of bush-type horticultural plants.

\section{CONCLUSION}

The existing prototype for harvesting such type of aromatic and medical plants is considering an important step to use better harvesting methods to handle these plants successfully. Although this prototype worked effectively to cut and transferee these plants, there were some problems during tests. A higher values of harvesting losses were notices and transferee efficiency incase of rosemary was low but generally, the total performance for the prototype was sufficient at this stage and by adding more improvements to the cutting and conveying systems, the machine can give us more effective and sufficient results.

\section{ACKNOWLEDGMENTS}

The research work here was part of the post-doctoral research of the first author in the Bologna University, Italy. The research funded through Research Fellowship, Dept. of agricultural economic and engineering. The author acknowledges the help and inspiration of all Stuff and workshop technicians in Dept. of Agricultural Economic and Engineering, Bologna University.

\section{REFERENCES}

Abdel-Azim, N.S., K.A. Shams, A.A.A. Shahat, M.M. El-Missiry, S.I. Ismail and F.M. Hammouda, 2011. Egyptian herbal drug industry: Challenges and future prospects. Res. J. Med. Plant, 5: 136-144.

Akay, A.E., O. Erdas and J. Sessions, 2004. Determining productivity of mechanized harvesting machines. J. Applied Sci., 4: 100-105.

Ammarellou, A., H. Saremi and F. Gucin, 2007. Evaluation of morphology, cytology and mycorrhizal relationships of desert truffles (Terfezia boudieri) in Iran. Pak. J. Biol. Sci., 10: 1486-1490.

Chang, D.I., H.S. Cho, S.Y. Zheng and S.S. Lim, 2004. Development and performance test of automated harvesting system for edible perilla leaves. ASAE Paper No. 041023, ASAE., St. Joseph, Mich.

Diekmann, J., 2002. Personal communication. International Centre for Agricultural Research in Dry Areas (ICARDA), Aleppo, Syria.

Erskine, W.F., J. Muehlbauer and R.W. Short, 1990. Stages of development in lentil. Exp. Agric., 26: 297-302. 
Funk, P.A. and S.J. Walker, 2009. Green chile pepper harvest mechanization. Annual International Meeting Held on June 21-24, 2009, Reno, NV. Paper No. 095518. http:/lasae. frymulti.com/abstract. asp?aid $=28552 \& \mathrm{t}=2$.

Guarrera, P.M., F. Lucchese and S. Medori, 2008. Ethnophytotherapeutical research in the high Molise region (Central-Southern Italy). J. Ethnobiol. Ethnomed., 4: 6-7.

Gurib-Fakim, A., 2006. Medicinal plants: Traditions of yesterday and drugs tomorrow. Mol. Aspects Med., 27: 1-93.

Hassani, H.S., A. Jafari, S.S. Mohtasebi and A.M. Setayesh, 2011. Investigation on grain losses of the JD 1165 combine harvester equipped with variable pulley and belt for forward travel. Am. J. Food Technol., 6: 314-321.

Huang, J., J. Wang and Y. Yu, 2010. The design of the automatic control system of the gripping-belt speed in long-rootstalk traditional chinese herbal harvester. IFIP Int. Federat. Infor., 317: 161-168.

James, L.G., W.E. Kee and T.L. Wootten, 2004. A mechanical harvesting index for rating the architectural characteristics of bush-type horticultural crops. ASAE Paper No. 041024, ASAE., St. Joseph, Mich.

Khayrallah, W.A., 1981. The mechanization of lentil harvesting. Commonwealth Agriculture Bureaus (CAB), Slough, England, pp: 131-141.

Koloor, R.T. and G. Kiani, 2007. Soybean stems cutting energy and the effects of blade parameters on it. Pak. J. Biol. Sci., 10: 1532-1535.

Natale, A.D. and A. Pollio, 2007. Plants species in the folk medicine of Montecorvino Rovella (Inland Campania, Italy). J. Ethnopharmacol., 109: 295-303.

Piccarolo, P., 2009. Herb machines, Machines for herbs (technical report). MMW No. 3/2009. Italy, pp: 64-69.

Pieroni, A., C. Nebel, C. Quave, H. Munz and M. Heinrich, 2002. Ethnopharmacology of liakra: Traditional weedy vegetables of the arbereshe of the vulture area in Southern Italy. J. Ethnopharmacol., 81: 165-185.

Rojanasaroj, C.P., R.N. Sirisomboon and W. Tangjaroenchai, 2003. Small soybean harvester implementing a two-wheel tractor. Proceedings of the International Conference on Crop Harvesting and Processing, Feb. 9-11, Louisville, Kentucky, pp: 37-58.

Sidahmed, M.M. and N.S. Jaber, 2004. The design and testing of a cutter and feeder mechanism for the mechanical harvesting of lentils. Biosyst. Engineering, 88: 295-304.

WHO, 2003. WHO Guidelines on Good Agricultural and Collection Practices (GACP) for Medicinal Plants WHO., Geneva, Austria, pp: 1-2. 